\title{
Right time, right place? The experiences of rough sleepers and practitioners in the receipt and delivery of personalised budgets
}

\section{Philip Brown}

\section{Introduction}

This chapter outlines one way in which personalisation has been implemented within the field of Homelessness within the United Kingdom (UK). The chapter draws on research findings from a longitudinal study which evaluated the delivery of an approach to allocate 'individual budgets' to people experiencing homelessness. The chapter outlines the effectiveness of the approach both in terms of outcomes for those who participated as recipients and its operationalisation by workers. The chapter makes a number of central points. Firstly, individual budgets, as described here, can be a particularly effective tool in reducing the length of time homelessness is experienced. Secondly, how such budgets are delivered is as important as the budget themselves. The skill of workers to work in innovative and creative ways is crucial to their success. Finally, there are inspiring findings arising which points to the pragmatic yet frugal approach by rough sleepers towards the use of individual budgets.

The 'personalisation turn' in health and social care policy within the UK appears to have had two main drivers. Firstly, a coping response by services seeking to adapt to the economic austerity measures introduced by the Coalition Government. Secondly, an ideological shift in the way policies influencing the commissioning and delivery of health and social care services were formulated. However, a shift to new ways of working and a movement towards more targeted services was no doubt hastened by an economic necessity largely as a result of the ending of the ring fence around the Supporting People Programme and the subsequent overall reduction in funding available for adult social care. As McCabe (2012) highlighted, many services, as early as 2012, were experiencing the same or higher caseload but with fewer staff available to meet the need. This has meant that organisations have had to prove their costeffectiveness to funders, particularly the Government, by focussing on ensuring the 'recovery' (i.e. reintegration into the labour market) of clients (Scullion, Somerville, Brown and Morris, 2015). An apparent consequence of this is that those people with most complex needs were also the ones finding it less easy to access support due to the challenging nature of their cases for already over-stretched workers (Cornes, Mathie, Whiteford, Manthorpe and Clark, 2015). At the same time an ideological shift to the discourse of personalisation has been gaining momentum. However, as Spicker (2013) points out although the term 'personalisation' is relatively new the concepts underpinning the ideology are not; pointing to the establishment of the quasi-market in social care in the 1980s and 1990s (Hudson, 1992; Le Grand and Bartlett, 1993) and the discourse utilised within the Department of Health's report 'Community Care: Agenda for Action' (Griffiths, 1988) as early manifestations of personalisation. Nonetheless, early policy documents more fully embracing the discourse of 'personalisation' included Improving the Life Chances of Disabled People (Cabinet Office, 2005), Opportunity Age (DWP, 2005) and Independence, Well-Being and Choice (DoH, 2005). The publication of Putting people first: a shared vision and commitment to the transformation of adult social care (DoH, 2007) marked a significant reform to social care policy. 
Although developed under the previous Labour government, the principles of the personalisation movement gained momentum within the work of Coalition government policy. Personalisation is now embedded as a key principle in the provision of care for specific groups within the Care Act 2014 (Cornes et al, 2015). The aim is to replace paternalistic, reactive care with high quality, personally tailored services; its philosophy is to give clients maximum choice, control, and power over the support services they receive and increasingly shape and commission their own services. The agency of the individual is often seen as pivotal to the personalisation approach by putting 'the person who needs support in control' of the services they receive (In Control, 2009). However, the centrality of 'individual choice' does not account for all the conceptualisations of personalisation. According to Spicker (2013: 1261) the definition for what personalisation means in terms of health and social care services can draw upon any of three competing interpretations. Those which refer to individualised assessments and responses; those which draw on the preferences of the user; and, those which attempt to reconcile both individualised process and individual preference. Spicker (2013) goes on to explain that in this latter interpretation 'the task of professionals is to facilitate and inform personal choice' (p.1262). Personal budgets are considered a key practice within the wider personalisation agenda and these are supposed to help ensure that people receiving public funding use available resources to choose their own support services. As the Department for Health guidance states:

'Personal budgets also need to be included in the law as they are important for making care and support personalised. If they are not in law it will be more difficult to offer them to everyone. While some local authorities are already making great progress in this area, legislation is needed to make it happen everywhere' (Department for Health, 2014:2)

Although it is argued that the concept of personal or individual budgets is not new (Spicker, 2013) individual budgets are intended to put the person who needs support in closer control of the services they receive (In Control 2009).

\section{Individual budgets and homelessness}

Homelessness has been a priority for policy in the European Union (EU) and the UK for some time. Successive governments have invested considerable resources attempting to reduce the variety of manifestations homelessness takes. As Johnsen, Fitzpatrick and Watts (2014) have outlined, over time there have been a steady increase in 'tough love' responses towards homelessness and those more recently characterised by increasing conditionality and assertive 'interventionist' approaches. Concerns have been raised as to the use of such approaches as those who are most excluded often have the most complex needs thus these approaches can lead to increasing vulnerabilities. However, as Johnsen et al (2014) have documented there has also been a rise in the development of approaches that have taken a less conditional approach particularly to working with those most 'entrenched' or who could be regarded as multiply excluded homeless.

In the homelessness sector, a commitment to personalisation was asserted in the Department for Communities and Local Government's (DCLG) rough sleeping strategy document 'No One Left Out: Communities Ending Rough Sleeping' in 2008. Within this, a range of measures were introduced including a commitment to pilot personalised 
support to long term rough sleepers (Hough and Rice 2010). The DCLG subsequently funded four national pilots in London, Nottingham, Northampton, and Exeter and North Devon. In social care, there are typically three elements of personalisation: a needs assessment; resource allocation to determine entitlement; and the development of a support plan. The pilot projects for homeless individuals receiving personalised support, however, were not bound to this method: in the London pilot for instance, formal needs assessment and resource allocation were removed and replaced by an obligation to appoint a broker and a commitment to spend their budget on things which would help them move into and retain accommodation (Hough and Rice 2010). The London pilot scheme aimed to test personalised budgets as a new way of working and showed that it can contribute to moving entrenched rough sleepers away from the streets. The target recipients of this pilot service were 15 individuals who were perceived as very resistant to moving off the streets and for whom standard services did not work. The project intended to find out if this group of people, who had been sleeping rough for between four and 45 years, would move off the streets, stay off the streets, and make positive changes to their lives. Thirteen people out of the 15 that were offered a personalised budget accepted it. They created a support plan with the project coordinator outlining what they would spend the budget on and how it would help them find and keep their accommodation (though they were not told what the maximum budget was). Clients bought things like bed and breakfast accommodation (if they preferred not to stay in hostels), pieces of furniture, a television, mobile phone, clothes, passport, a hearing aid, courses, and travel costs. Purchases had to be approved by a commissioner but administration was kept to a minimum and decisions were usually made within a day. Though professionals expected clients to spend the money without making any commitment to finding accommodation, the opposite actually happened: clients found it hard to identify what they should spend the money on, spent little, and were reluctant to buy more expensive items. The outcome of the pilot was that seven people remained in accommodation four to 11 months after moving in. Two more were planning to go into accommodation but the remaining four had disengaged. For those that maintained their accommodation, there was additional benefits such as new welfare benefits claims, improvements in mental and physical health, engagement with substance misuse services, reduced alcohol use, and several were making plans away from the streets, re-engaging with family members, and were developing independent living skills such as cooking and budgeting. However, it was the choice and control that the budgets offered, combined with intensive work from a single trusted worker, that were seen as critical to the success of the pilot (Hough and Rice 2010). Overviews of the design, process and outcomes from the Exeter and North Devon, Northampton, and Nottingham pilots can be found in Homeless Link (2012a, b and c).

\section{The Individual Budget projects in Wales}

Following on from these initial pilots the Welsh Local Authority Homelessness Network sought to explore new ways of tackling long-term homelessness by embracing the individual approach. Five areas, which mapped onto local authorities, across Wales were allocated funding. The projects within each of these areas were asked to focus their work on the most difficult to accommodate individuals. Working within existing support structures, each area would have access to an individual budget. Each area was encouraged to develop their work in ways which suited their client group, the service structure in their area and the broader context of their locality. Each project had a 
budget of around $£ 20,000$ and these were to be used as budgets for individual rough sleepers. Some small additional funds were available to cover limited management and/or staffing costs incurred by the lead organisations. Workers selected to work on the project were already in post and in all except one case merged the work on the project with their existing (if reduced) caseload.

An evaluation of the projects in Wales was undertaken by the author and the full report contains a detailed account as to the design, process and achievements of the project (Brown, 2013). The evaluation employed a predominantly qualitative longitudinal approach which was contextualised by integrating secondary information and embracing a collaborative approach where emerging findings were relayed to practitioners within learning and sharing workshops over the course of the evaluation. Interviews were carried out with both the managers/coordinators of the project in each area (five people) and a selection of the support workers in each project area (a total of 13 support workers). Efforts were made to interview them at three separate intervals of the project: commencement, mid-term (around nine months), and the end of the projects. In total there were 41 consultations with service providers over the period of the evaluation. In addition, a total of 17 people in receipt of individual budgets were interviewed. The research team worked with support workers to identify respondents for the study. Where possible attempts were made to interview people twice over the course of the projects: at or near their initial engagement and finally at or near the end of the project. However, not all clients were able to take part in both consultations. Eleven respondents took part in both initial and final interviews with the remaining six respondents only able to take part in the initial interviews. A total of 28 separate interviews were carried out with clients over the course of the evaluation. Quotes are presented below to illustrate particular points which the identity of the speakers protected by the use of pseudonyms.

The vast majority of those people involved in the evaluation had been rough sleeping immediately prior to being attached to the project. A number of coordinators and support workers described the 'model' participant as someone for whom all other attempts at helping people secure stable accommodation had failed and who had other complex needs and interdependencies. Most could easily be described as experiencing multiple exclusion homelessness (see McDonagh, 2011). Those people who were selected for the project by services had very often spent periods in prison, were heavy alcohol drinkers and/or significant substance misusers. Most people were well known to many agencies within the areas in which the project was based. Those selected were often characterised as having exhausted every other option for financial and housing support. The people involved in the interviews for the evaluation certainly reflected this background. For example, from the interviews with individual budget recipients, Bob talked about how he spent two years living in a tunnel, Carl talked about trying to live in a local park and Harry talked about how he tried to find places in and around a local church.

\section{Did it work?}

Asserting the effectiveness of the projects is far from simple as the end-point of the evaluation coincided with the conclusion of the funding for the initiative therefore longterm successes are, at this point, impossible to ascertain. However, in terms of their 
success in getting the most excluded into stable accommodation there were some clear immediate successes. A total of 79 people were involved in the individual budget projects. Of these it was estimated that a total of at least $33(42 \%)$ were in a position of having achieved relatively stable accommodation (living in some form of low support accommodation, living with a partner or supported by their family, living in own accommodation with no or little support etc) at the conclusion of the project. Of the remainder, a large number (around 40\%) were accommodated in some form of temporary accommodation. In addition to achieving accommodation there were also non-accommodation related successes noted by workers such as a reduction in alcohol and substance misuse, increased self-esteem and self-confidence, an increase in trust and engagement with support services, more appropriate engagement with health and support services. It was difficult for the evaluation to achieve a definitive conclusion as to the cost-effectiveness of the projects due to the scale of the evaluation carried out. However, in the very broadest sense the projects did appear to offer good value for money. As an example, although it was initially envisaged that around $£ 80,000$ would be spent on implementing the projects as a whole, the actual spend was less than half at just over $£ 34,000$. It was also anticipated that this would be spent on around 50 individuals when in practice 79 people were affiliated with the projects. This resulted in average expenditure per recipient of the budget across all areas of $£ 434$. This, of course, is in addition to staffing costs which were not quantified. In addition, workers cited savings to the public purse as a result of reduced levels of criminality and reactive health care as a result of their work but these were not able to be quantified by the evaluation. In terms of the difference the approach made to individuals, those clients who were aware that they were on a 'special' programme (it should be noted that some clients were in the early stages of recovery from a range of issues and were not always cognisant that they were in receipt of an individual budget) and had 'gone in' to settled stable accommodation often directly attributed this success to the project. Where stable accommodation had not been achieved it could be argued that the individual budgeting approach might not have been successful. However, from consultations with staff and clients it was repeatedly stated that their accommodation status at the end of the projects often hid a complexity of positive personal developmental experiences. In almost all circumstances - even where people were still rough sleeping - there were tangible improvements reported to their overall situation. Examples of individual successes included:

- The development of new and more positive social networks not defined by mutual drug and/or alcohol use.

- A reduction in levels of alcohol and substance intake which, for the individuals concerned, was often an enormous success given what tended to be described as their significant and relentless use prior to engaging in the projects.

- Exercising an ability to save some of their income.

- More regular positive contact with family members and dependents.

- Cessation of sex work.

- Increase in ability to engage in personal care.

- Volunteering at hostels, as peer mentors and at local schools.

- Noticeable improvements in self-esteem and self-confidence when in social interactions. 
Although there was overwhelming positive support for the individual budget approach, attributed largely to its usefulness of developing person-centred solutions to problems, there was a strong message from workers, and clients themselves, that the approach would not be suitable for everybody. Indeed, there were a number of occasions where things had not gone as anticipated. Common downsides of the use of the budgets included:

- Accommodation was damaged by the client,

- Bought items being damaged or stolen by 'friends' and associates,

- Selling bought items on.

According to the support workers interviewed such eventualities appeared few and far between. Still we see evidence of what Padgett, Henwood and Tsemberis (2015) see as 'small victories' in that in the majority of occasions the clients remain engaged both with the individual budget approach and, perhaps most importantly, with their support worker.

\section{Organisation and administration of the individual budgets}

In most cases the support and the money received worked in coordination, either explicitly or implicitly, with a support plan which was developed between a support worker and the client. The budget within one of the areas however was reported as not being tied to a support plan as it was designed in order to be flexible to best respond to individual needs. None of the pilot areas discussed the total amount of money available with their clients.

You've got to remember they know we can get funds for them. They don't know how much we can get. They don't know where it's coming from. They don't really know it's solely for them. (Support worker)

Furthermore, it was apparent as time went on that as new clients were brought onto the project that not all clients were informed they had access to an individual budget. Instead the project was often referred to in more ambiguous terms e.g. a new scheme, new programme etc. The way in which support workers framed the individual budget project was reflected in the responses provided by clients in the interviews. A number of people said that they had become aware of the project over time. People sometimes said their support worker had not told them about it, or not gone into details or they simply assumed it was another fund to help them pay for housing costs. For example, a number of clients expressed confusion about why they were being consulted in such depth about the funding they had received:

Alistair: Like I say, I had a brief meeting with her. We had a brief discussion about bonds and then they said, bed and breakfast as well. I don't see this as a pot of money which I've got control of. I don't know the limits of it all or whatever.

Such practice raise questions as to whether the approach described here accurately reflects the principles of personalisation outlined earlier in the chapter or whether this approach might be best seen as 'personalisation-lite'. 
On the other hand, there were other people who appeared fully aware of the project as well as the principles and scope of the individual budget approach for example Karen:

Karen: Thinking about it, I thought it was good. It helped me get back onto my feet without like, with obviously how to use it wisely and what to do with it and not obviously right now with the shared accommodation, there is not a lot we can do with budgeting just yet. When I was transferred into my safe place, they had more with budgeting than with everything else, with decorating and things like that. I'm still in the programme with it at the minute. I think it's-I thank the people who have helped them to help others like myself and others in the same situation as I'm in.

At the outset there was some concern, by workers, about the lack of guidance as to what the budget could be spent on. People often wondered about what the right thing to be purchasing was and whether certain items would be allowed. Workers in one of the localities took a very broad inclusive view of what was permissible and workers here were encouraged to think broadly and adhere to being pragmatic by allowing spend on a range of areas, the guiding principle was that the money, "...can't be spent on anything immoral or illegal". However, in a couple of other localities there was some initial uncertainty as to whether the budget could be spent on repaying debts or on deposits for accommodation. However, over time, once coordinators and workers had become more experienced with the individual budget concept, it appears many of the initial restrictions were relaxed. Once the initial anxiety subsumed, where possible, ideas began to be co-produced with clients in order to try and facilitate the unlocking of some of the complexities. For example one support worker recounted their particularly successful work with one of their clients:

He didn't say, can I have a bus pass. It was like, what's your main sort of hurdle in moving on with things and it was he couldn't access his family, he's got a young son and sister, because he couldn't afford to go backwards and forwards to see them. We thought, well, maybe we could do a bus pass for him to be able to do that and then it just went from there really and he rebuilt relationships which then has knock on effects. He now since moved closer to Bridgend. That was one of the things that he was really struggling with at that point and felt that if that was improved then other things may improve, which it did. (Support worker)

For this client, the bus pass was subsequently replaced with a bicycle, in order for there to be a more sustainable solution preparing for the end of the pilot, which was purchased out of the individual budget funds.

There were a variety of reasons support workers gave for purchasing the items they did with their clients. Many of the workers who supported clients through the project reported that the strength of the individual budget approach was the access to funds to address housing costs which their clients would otherwise not have recourse to. This, for some, meant that a route into accommodation could be provided for clients when the individual budget was spent on providing bonds and settling housing debts. Similarly, landlords were also seen as more amenable to the notion of clients living in their properties when they came with the added support provided by workers. On at least one occasion the budget was used to help a client remain within bed and breakfast 
accommodation while the local authority decided whether they had a duty towards him. The authority eventually decided in his favour and he was able to obtain independent accommodation, the alternative would have meant a return to rough sleeping. Mitigating the potential for clients to exercise their 'negative agency' (Hoggett, 2001) was a central reason for suggesting or encouraging the purchase of certain items. Purchasing things that would keep clients distracted and away from, what was perceived as, negative social networks was a major reason for using the budget. Items such as TVs, fishing tackle, DVD players etc. were all purchased with the aim of keeping people away from boredom, breaking up existing social networks and generally occupying people's time in a non-self-destructive way.

However, using the budget as part of an effort to develop and maintain trust with the client was a core use of the budget in almost all cases. Being able to agree to a purchase of an item and actually follow through with it was a core component in the development of trust, as well a shared shopping experience to purchase items. As such, common areas of expenditure tended to be practical and essential things, often inexpensive, including food, sensible footwear, waterproof jackets, phones, etc.:

It's all similar items that come up again and again that people want, phones, jackets, boots, footwear. Very basic stuff. There is nothing apart from the lampshades here and there, everything is essential. That's not surprised me about it, but I think that's really stood out that nobody wants anything frivolous at all. Everything that people want is practical. It's just practical. Literally, my shoes are falling apart, so I need a new pair of shoes. I will keep the old ones for begging, because I get more money then, which I think is good. That is what people want. It's practical stuff. (Support worker)

Engaging in the pilot and making progress

Much of the support for the individual budget approach from workers was grounded in the perception that it was seen as a welcome turn to an assertive outreach role (Witheridge, 1989). Having access to the budget was seen as an important part of the approach and regularly described as the 'hook' or 'carrot' which helped get people engaged with the support worker. As one coordinator explains:

It doesn't matter what you are actually buying with the money, but it's a carrot to bring people into support when they wouldn't normally be engaging with support workers. We've got support available now, but for whatever reason they are not engaging with it because it's not what they want or it's provided in the way that they want and the budget basically allows us to sort of get involved with that rough sleeper, because if they tell us they want something we can go ahead and provide it. (Coordinator)

It was clear that having access to a new way of resourcing potential interventions, or even covering basic incidental expenditure for people, gave workers options that had not before been available to them.

Although the focus of the projects was the introduction of the individual budget, what emerged as the crucial element in making the projects operationally effective was the person-centred increase of time and support from a support worker, a key finding 
shared with Hough and Rice (2010). Such rapport was seen as a prerequisite to allow for a trusted relationship to develop between support worker and client. Similarly, the Association of Directors of Adult Social Services (ADASS, 2012) in the context of older people suggests that what matters most is not who provides the support, but the nature of the support and the rapport established with those providing it. Many workers spoke of the value that having meaningful time with their clients had on the co-development of effective interventions; this was enacted in various ways. To some it meant accompanying clients to appointments, to others it included shopping trips to help them make decisions and follow through with their purchases. The relationship clearly meant a lot to many of the people. Notions of 'respect', 'support' and 'trust' were some of the key concepts mentioned by clients about their relationship with their support worker. Although the time spent with each client differed on a case to case basis, it was reported that there was a noticeable increase in the time devoted to clients on the project when compared with 'regular' clients. As one support worker describes this was as much as 30-40 per cent more time per client:

My clients, my regular clients I see every day. However, because he's here every day. I do visit him in his tenancy as well, which I wouldn't do with my other clients, necessarily... Percentage wise, I suppose you would call it 30 per cent, 40 per cent more. (Support worker)

Once the initial anxiety around what was permissible under the individual budget approach had subsided, workers described a whole range of ways in which they had begun to work and feel more creative in their approaches to dealing with the challenges clients were facing. As one support worker reported:

I've learned to be more flexible and look outside the box for things. People are all different. There are little things that you can do that will make a big impact on people and finding what suits them, if you can do it in your role, then try and do that. (Support worker)

As well as becoming more creative, workers, who were used to working within a more reactive service, began to adopt more assertive preventative practice in order to attempt to stop challenging situations getting worse. Often this brought to light frustrations workers had with what they perceive as the 'revolving door' of their usual practice where clients simply present at one service and then another with few apparent sustainable successes. One way in which the creativity was made possible was via a certain degree of supported autonomy provided for workers by the coordinators, or management structure. This was seen, by support workers, as an important part of the structure in order to allow for immediate and creative responses to take place. At the same time however, it was also noted that a support network should be wrapped around workers as a way in which people, who are working with individual budgets, could draw upon support and professional stimulus if required. One support worker in particular reported feeling isolated in their work and needing some input to help shape her decisions:

I think it's been a bit hard for me, because I don't have anyone else to bounce off, you know, the problems that they have and even though I do have supervision with my line manager, how is IB [individual budgets] going? It's fine. Whereas I know if 
I was in an office and if I'm working with people that were on the same project as we'd be talking about things and maybe give each other advice or support.

\section{(Support worker)}

\section{Partnership working}

As Cornes, Joly, O'Halloran and Manthrope (2011) have stated some people, particularly those seen as experiencing multiple exclusion homelessness, do not fit neatly into the compartments provided by many services. Many people have multiple or polyphonic identities (Hermans, 2001) and it is unfortunately not unusual to find people who are homeless, drug users, sex workers, and have mental health issues all at the same time. As such homelessness is seen as presenting particular difficulties for joint working. Indeed, as Oldman (1997: 241) suggests, 'assessing need and delivering health and social care services to an itinerant population is immensely difficult'. Within a UK context Roche (2004) highlighted the difficulties that exist for both service users and providers in terms of navigating through the various services available. There are also issues around the different ethos of organizations and cultures of provision, which can create problems when looking at the integration of services (ibid). All areas involved in the Individual Budget pilots recognised the existence of multiple identities and complex lives and attempted to bring together a range of partner agencies in order to help with the delivery of the project. However, there were challenges faced in certain areas and differences between the areas as to how effective these partnerships were. It appears that the effective delivery of the projects was more straight-forward in areas where inter-organisational partnerships were already strong or where the activity was coordinated by a single full-time support worker, as was the case in one of the areas. However, it was clear that with careful planning a range of support work models could work effectively. One area relied on a small number of support workers within particular agencies to deliver the project. This appeared well coordinated with evidence of significant communication between the partners and a distinct sense of joined-up working. However, a small number of workers did make note of the added strain the individual budget work had on their workloads. Workers talked about how it was manageable as a pilot scheme but expressed concern about the sustainability of the approach if there was no added capacity built into their work. There was no evidence of the fear expressed by Williams and Sullivan (2010) that collaborative working was seen as a 'bolt on' activity as a result of a reduction of available resources. Although agencies appeared very content to work together and communicate effectively it is possible that as these were time-limited projects this may have contributed to staff remaining engaged and adopting special arrangements in order to deliver the projects effectively. For instance, one organisation talked about having some 'windfall capacity' as a worker had her hours increased from part-time to full-time during the delivery of the project.

One of the interesting ways the individual budget project contributed to more productive partnership working was the framing of the project as a 'special programme'. Such framing by workers to 'external' agencies and organisations (e.g. landlords) seemed to create confidence that 'high risk' clients would get extra support. This ultimately allowed the support workers to have access to a greater range of accommodation options than would otherwise be the case: 
The one thing we have found with the $I B$ [individual budgets] is that it's actually opened doors for people. It's seen as this strange project that other agencies don't really know that much about. It's allowed us to carry on working with people so there is none of this cross funding thing. Agencies sometime say that "we don't want to be abandoned with this person, because they are very very difficult" and we could say, "well, no, we will support them as well". They then have multi agency support whereas people had said, "well in that case, we will take them on." And we say "we will work with them. We will find them accommodation. But you must do the support as well." And so it's opened a lot of doors with people. All these people that we've accommodated we wouldn't have done without the IB. (Support worker)

In one of the areas however the project was not successful and did not really get underway. Here, once the project had concluded we took the opportunity to review the outcomes in this locality and it was clear that the design of the project in the area meant that there was ineffective inter-agency partnership working and a lack of staff capacity:

I think perhaps we were a bit naïve in thinking that there would be enough capacity in these different projects to be able to do it, working with chaotic people. When they go from one place to another everything changes... With hindsight it would have been good to look at the makeup of the projects [existing activities] beforehand and any possible duplication or whatever. At the last stage before finishing we were saying, let's try and get this money and we were saying to the partners, look, can you reconfigure at all? Can you reconfigure what you are doing or can you release some hours or whatever. There was a pressure on it to do it then, because we could lose the funding. They managed to come up with it, because there was that pressure. That would have been good at the beginning, I guess. (Project coordinator)

\section{Conclusions}

By drawing on the experiences and views of those involved in designing, delivering and receiving individual budgets this chapter has raised several issues for how the turn to personalisation in social care is being delivered in practice within the context of homelessness. The material provided here demonstrates that individual budgets can be seen as a particularly effective tool in both reducing some of the structural barriers in place and enhancing the agency of those in receipt of budgets. The projects carried out in Wales indicate potential cost-effectiveness and positive outcomes for getting people off the streets, away from precarious housing and reducing a wide range of harmful issues. There was also qualitative evidence of a range of psycho-social benefits such as increasing self-esteem, disrupting negative social networks and a reduction in substance misuse.

It is not clear how much of the success is due to the selection of the support workers chosen to work on the pilot by the lead organisations. However, what is clear is the approach and skills of the support worker is crucial. It was seen that those workers most entrenched in their current practice, and who are less open to innovating in their work, would not necessarily have the same level of positive outcomes seen by other workers. As a consequence the individual budget approach places significant demands 
upon the skills and professionalism of staff. Workers require patience and capacity in order to remain in contact with individuals in spite of speed bumps and crisis. These findings compliment previous research which has emphasised the crucial role played by such workers in the delivery of support to people with complex interdependent issues (Cornes, et al, 2011). Furthermore, a large part of the successes of these pilots is down to the ability of support workers to balance responsiveness with proactive working. These findings continue to point to the need of untapped potential within 'housing support workers' to make material differences to the lives of the most excluded and who, as Cameron (2010) argues, continue to feel the vacuum left by qualified social workers.

However, there was a general lack of awareness from clients as to presence of the programme, the budget and the size of the resource they have recourse to. As such, this individual budget approach excludes many of the key factors intrinsic within the ideology of personalisation. Although this did not appear to present many disadvantages to the delivery of the pilots, it is not known how far the factors of choice, control and power were mobilised. This perhaps suggests that not all areas of social care suit a 'pure' approach to implementing personalisation. Instead the ideology could be adapted in order to tailor approaches along a spectrum of personalisation in order to suit a specific context. Furthermore, a number of the issues around the inability of systems to respond quickly, difficulties associated with permitting creative working and tensions around inter-agency working raise questions about the ease with which a pure approach to personalisation can be operationalised in the homelessness sector.

Moreover, this experience of individual budgets highlights that the process of expenditure is as important, if not more so, than the item being purchased. This study illuminated the frugalness of people who are homeless and have relatively few personnel possessions. It showed the act of shopping for mundane items such as clothes, a bed and cutlery can have reportedly life changing and emancipatory meanings for people. At the same time the process of sharing the experience of exercising choice with someone helps shape trust between the worker/organisation and individual, and gradually supports the ability of people to self-direct their own lives. The findings discussed here would tend to concur with the thoughts of Blackender and Prestige (2014) and Cornes et al (2015) that it is ' person-centred care' and not 'personal budgets' that people want' (p.9). As such the individual budget approach cannot be separated from the role of the support worker in their care of clients. Where there were positive outcomes the budget and support work role appears symbiotic and any reduction in one of these factors may impact on the effectiveness of the other. These findings support the assertion by Homeless Link (2013: 30) that,

'Personalised approaches seem to be most effective where workers are given time and flexibility to support clients as they require, with no time bound targets to achieve results with small case loads'

As such the projects in Wales provide a good example of what Cornes, Joly, O'Halloran and Manthrope (2011:4) have called the so-called 'holy grail' of community care policy.

\section{References}


Association of Directors of Adult Social Services (2012) The Case for Tomorrow. London: ADSS

Blackender, L and Prestige J. (2014) Pan London personalised budgets for rough sleepers. Journal of Integrated Care. 22(1) 23-26

Brown, P. (2013) Right time, right place? An evaluation of the Individual Budget approach to tackling rough sleeping in Wales. Welsh Government/University of Salford. Available at http://usir.salford.ac.uk/35792/1/Individual\%20budget\%20report.pdf accessed $07 / 10 / 15$

Cabinet Office (2005) Improving the Life Chances of Disabled People. London: HMSO.

Cameron, A.M (2010) The contribution of housing support workers to joined-up services Journal of Interprofessional Care, vol 24(1), pp. 100 - 110.

Cornes, M., Joly, L., O'Halloran, S. and Manthorpe, J. (2011) 'Rethinking Multiple Exclusion Homelessness: Implications for workforce development and interprofessional practice. Summary of findings', Swindon: Economic and Social Research Council.

Cornes, M., Mathie, H., Whiteford, M., Manthorpe, J. and Clark, M (2015) The Care Act, Personalisation and the New Eligibility Regulations: A discussion paper about the future of care and support services for homeless people in England. Kings College London. Available at

Department for Work and Pensions (2005) Opportunity Age: Meeting the challenges of ageing in the $21^{\text {st }}$ century. London: HMSO.

Department of Health (2005) Independence, Well-Being and Choice. London: HMSO.

Department of Health (2007) Putting people first: a shared vision and commitment to the transformation of adult social care. London: HMSO.

Department of Health (2014) Factsheet 4 The Care Act: personalising care and support planning. Available at

https://www.gov.uk/government/uploads/system/uploads/attachment data/file/366 084/Factsheet 4 - Care and support planning.pdf accessed 08/03/2016

Griffiths, R. (1988) Community Care: Agenda for Action, London, Department of Health and Social Security.

Hermans, H.J.M. (2001) The Dialogical Self: Toward a Theory of Personal and Cultural Positioning. Culture and Psychology, 7, 3, 243-281.

Hoggett (2001) Agency, rationality and social policy, Journal of Social Policy, 30, 1: 3756.

Homeless Link (2012a) Exeter and North Devon Council's Individual Budget Pilot. Available at: http://homeless.org.uk/Exeter-north-devon-pilot accessed 11/11/13. 
Homeless Link (2012b) Northampton Personalisation Pilot with Socially Excluded Groups. Available at: http://homeless.org.uk/northampton-personalisation-pilot accessed 11/11/13.

Homeless Link (2012c) Nottingham City Pilot and Framework HA Pilot, Available at: http://homeless.org.uk/Nottingham-personalisation-pilot accessed 11/11/13.

Homeless Watch (2013) A High Cost to Pay: the impact of benefit sanctions on homeless people. London: Homeless Link.

Hough, J. and Rice, R. (2010) Providing personalised support to rough sleepers: An evaluation of the City of London pilot, York: JRF/Broadway.

Hudson, B. (1992) Quasi-markets in health and social care in Britain, Policy and Politics, 20(2), pp. 131-42.

In Control (2009) An Introduction to Self-Directed Support. Factsheet 1. Available at: http://www.in-control.org.uk/media/16696/01. per cent20introduction per cent20to per cent20self-directed per cent20support per cent202011 per cent20v1b.pdf accessed $11 / 11 / 13$.

Johnsen, S., Fitzpatrick, S. and Watts, B. (2014) Conditionality Briefing: Homelessness and 'Street Culture': York: University of York.

Le Grand, J. and Bartlett, W. (1993) Quasi-Markets and Social Policy, Basingstoke, Macmillan.

McCabe, J. (2012) Staying afloat Inside Housing, 13th July http://www.insidehousing.co.uk/staying-afloat/6522720.article

McDonagh, T (2011) Tackling homelessness and exclusion: Understanding complex lives. York: Joseph Rowntree Foundation.

Oldman, C. (1997) Working together to help homeless people: an examination of interagency themes, in R. Burrows, N. Pleace and D. Quilgars (eds) Homelessness and Social Policy, London: Routledge, 229-42.

Padgett, D., Henwood, B.F. and Tsemberis, S. (2015) Housing First: Ending Homelessness, Transforming Systems, and Changing Lives. Oxford: Oxford University Press.

Roche, M. (2004) Complicated Problems, Complicated Solutions? Homelessness and Joined-up Policy Responses, Social Policy \& Administration, 38 (7): 758-774.

Scullion, L., Somerville, P., Brown, P. and Morris, G (2015) Changing homelessness services in Stoke-on-Trent: revanchism, 'professionalisation' and resistance. Health \& Social Care in the Community. 23(4), 419-427 
Spicker, P. (2013) Personalisation Falls Short. British Journal of Social Work, 43, 12591275.

Williams, P and Sullivan, H (2010) Despite all we Know about Collaborative Working, Why do we Still Get it Wrong?, Journal of Integrated Care, 18, 4, 4 - 15

Witheridge T.F (1989) The Assertive Community Treatment Worker: An Emerging Role and its Implications for Professional Training. Hospital and Community Psychiatry 40 (6), 620-624 